\title{
Erratum: Gough et al (2017)
}

In the article by Gough, L.A., Rimmer, S., Osler, C.J., \& Higgins, M.F. (2017). Ingestion of sodium bicarbonate $\left(\mathrm{NaHCO}_{3}\right)$ following a fatiguing bout of exercise accelerates postexercise acid-base balance recovery and improves subsequent highintensity cycling time to exhaustion, International Journal of Sport Nutrition and Exercise Metabolism, 27(5), 429-438, doi: 10.1123/ijsnem.2017-0065, we did not accurately reflect several content and layout corrections which were needed.

These include:

(a) The key for Figure 1 was erroneously included for Figure 3 (and not for Figure 1).

(b) The abbreviation for PRE was missing from the Figure 1 key.

(c) Figure 3 contained two indicators $(+)$ which were not necessary.

The online version of this article has been corrected. We sincerely apologize for these errors. 